\title{
Customers of place: exploring interregional migrant collectivities
}

\author{
Djavlonbek Kadirov and Arti Triveni \\ Business School, Faculty of Business and Computing, \\ Eastern Institute of Technology, Napier, New Zealand
}

\begin{abstract}
Purpose - The aim of this research is to explore how and why different migrant groups see different values in places they move to. Understanding these values and also the conditions in which these values are shaped will help in targeting marketing effort.

Design/methodology/approach - The hierarchical and K-means cluster analyses were instrumental in identifying different migrant clusters. Planned contrasts were employed to compare related pairs of clusters. The logistic regression analysis identified several determinants of cluster membership likelihood.

Findings - Four different internal migrant clusters are identified in the Hawke's Bay region of New Zealand. These are Material Success Seekers, Community/Environment Folks, Apathetics, and All-rounders. The former two express a fragmentalist lifestyle. Material Success Seekers emphasise regional business opportunities while being indifferent to social and natural resources. In contrast, Community/Environment Folks emphasise social and natural resources while maintaining indifference to business opportunities. In turn, the latter two clusters make up a holistic lifestyle: All-rounders consider all three major characteristics of the region to be important while apathetics totally deemphasise these characteristics. The planned contrasts show that demographics are instrumental in predicting differences between related clusters but not helpful in distinguishing the identified lifestyles.
\end{abstract}

Research limitations/implications - The limitation of this investigation is that the important constructs used to cluster migrants are not well calibrated, although the reliability scores appear to be satisfactory. Moreover, the use of four-point importance scales does not allow attaining a greater level of construct sensitivity. The research method is unique in a sense that the cluster analysis and the planned contrasts are applied to examine contrasting values of migrant collectivities.

Practical implications - A number of specific practical challenges need to be resolved by the regional decision makers in order to enhance place satisfaction by internal migrant collectivities. First, the regional and city councils will need to tailor different services, facilities, and public spaces to appeal to different requirements of migrant clusters. Second, the region's settlement support agency should provide migrants with relevant, focused, and differentiated information about available services and resources to suit their various life goals, aspirations, and values.

Originality/value - This investigation tackles the problem of lacking theoretical and empirical research foundation on internal migration as a marketing phenomenon. Moreover, it is unique in its approach of conceptualising migrant segments as cultural phenomena, that is, interdependent collectivities that form on the basis of contrasting values.

Keywords Immigration, Marketing, Market segmentation, Lifestyles, Cluster analysis, New Zealand

Paper type Research paper

Place marketing is one of the important functions in the broader framework of place management (Ashworth and Voogd, 1990; Kavaratzis and Ashworth, 2008). Researchers suggest that it is imperative to market places to potential customers

Journal of Place Management and Development

Vol. 3 No. 3,2010 pp. $167-181$ (c) Emerald Group Publishing Limited $1753-8335$ 
JPMD

3,3

168
(Kotler et al., 1993; Kotler and Gertner, 2002). Kotler et al. (1993) argued that the adaptive capacity of place stakeholders is much slower than changes in environmental factors that shape and reshape the place's comparative advantage over other places. Therefore, planned continuous development and accurate communication of place characteristics to stakeholders are crucial (Ashworth and Voogd, 1990; Madsen, 1992).

To be considered marketing, a management situation must involve at least three components: a product, decision makers, and customers. A place (e.g. towns, cities, regions, and countries) can be considered as a brand or product (Kotler and Gertner, 2002). In the context of this research, the product is the Hawke's Bay region of New Zealand. The decision makers are the employees and managers of regional and national economic, business, and social development departments, urban and regional development offices, tourism, infrastructure, utilities companies, chambers of commerce, foreign trade and relations offices, and private businesses. Kotler et al. (1993) differentiated four types of place customers: visitors, residents and workers, business and industry, and export markets. Existing research broadly documented issues, strategies, and challenges related to marketing places to visitors, tourists, residents, businesses, and export markets (Anderson et al., 2009; Jiwa et al., 2009; Kavaratzis and Ashworth, 2008; Kotler and Gertner, 2002). However, there is a lack of research that conceptualises internal migrants as place customers.

Internal migrants are the people who move from one place of residence to another within the same country. In this research, we define internal migrants to be the individuals who have moved to the Hawke's Bay region from other regions of New Zealand or other countries. Internal migration is an important socio-economic process that has much greater impact on development trends that shape localities than international migration (DeWind and Holdaway, 2008). Internal migrants are highly involved not only in assessing place attributes but also in obtaining insiders' information about comparative regional opportunities (Greenwood, 1997). Recognising that different characteristics of place would have different levels of appeal to different groups of internal migrants, we would like to emphasise that internal migrants should not be treated as a homogeneous group. Also, the degree to which these characteristics are important is of interest.

The objective of this paper is to identify how and why different migrant clusters value different place characteristics in the Hawke's Bay region. This research shows that migrant collectivities are not only different in what they value but also interrelated via direct value opposition. As the process of social distinction creation gives rise to alternative lifestyle values, targeting the needs of a particular migrant cluster will have substantial simultaneous effects on other clusters.

\section{Theoretical background}

Prior research indicates that place is not a simple product but a complex social and cultural object towards which individuals develop different attitudes and values (Kavaratzis and Ashworth, 2008; Kotler and Gertner, 2002). Hence, it would be unwarranted to treat internal migrants as a homogenous group. Rather, the expectation is that migrant groups are clustered and these clusters hold different views on how to value a place (DeWind and Holdaway, 2008). Besides, valuing a complex object is not only associated with individual cognitive operations but also associated with social processes of social categorisation and identity building (Tajfel, 1981; Turner, 1985). 
Social identity theory

Social identity theory is based on a body of ideas that in essence indicates that categorisation of people into different groups, priori to individual interaction, promotes ingroup-outgroup comparisons and differential valuation (Tajfel, 1981; Turner, 1985; Turner et al., 1987). Furthermore, research indicated that need to attain social identity motivated people to define themselves in terms of their group membership. Research participants tended to express different views on and develop differential value judgements about observed realities (Turner et al., 1987). Besides, it is the need for positive social identity that was a driving force in creation of distinctiveness of ingroups versus outgroups in matters of valuation and judgment. The theory showed that when social categorisation becomes salient, people do not see themselves as personalities with idiosyncratic characteristics. Rather, they perceptually emphasised similarities to ingroups and distanced themselves from outgroups. Applying this notion to migrant groups, one can expect that migrants will be different in terms of their attitude toward the place due to three factors:

(1) the need for social identity;

(2) minimising similarities within a particular cluster; and

(3) maximising differences with other clusters, especially those differences that relate to place valuation.

\section{Cultural distinction}

Bourdieu (1984) analysed consumption as a process of expressing social distinction. According to his theory of cultural distinction, consumers purposefully maintain differences in the judgment of tastes with regard to cultural products to differentiate themselves from other groups of consumers. In other words, the theory proffers that tastes are not objective. Rather tastes become a tool of social differentiation. Tastes are formed in opposition to the tastes of an opposing social class. In this sense, a particular social class is related to another social class through taste distinctions.

Bourdieu (1984) argued that cultural tastes create distinctions that help members of society to mark their social positions. He argued further that taste, as "an acquired disposition to differentiate", cannot be associated with language or consciousness as it is inaccessible to introspection or personal will (p. 466). By conducting an impressive ethnographic study of France, he observed how tastes become part of "habitus" that can broadly be defined as embodied social structures based on classifying and judging objects and events according to one's social position. Bourdieu highlighted the fact that social positions, individuals' perception of their relative places in social milieus, predetermined one's reaction toward consumption objects. The impact of a social class structure on individual practices was moderated by habitus. An interesting finding in Bourdieu's investigation was that a social class's tastes (i.e. value judgments) are evinced in opposition to those of another social class.

\section{Migrant groups as consumer collectivities}

Consumer collectivity consists in "groups of people who have been socialised in similar conditions [...], are embedded in similar social relations [...], and so tend to have similar cultural understandings" (Holt, 1997, p. 326). Two characteristics of collectivities differentiate them from consumer communities. First, collectivities do not have to have
Customers

of place

169 
JPMD 3,3

a formally organized structure (Holt, 1997), whereas communities are united via consumer cultural acts such as maintaining common rituals, following shared traditions, acting collectively, and feeling strong moral obligation to the community (Muniz and O'Guinn, 2001). Second, membership in collectivities is not based on conscious decision making, whereas communities are marked through "consciousness of kind", i.e. shared perception of being part of a group (Muniz and O'Guinn, 2001, p. 413). Migrant groups are more like consumer collectivities because they are not formally organised or based on "consciousness of kind". Using, Holt's terms, we argue that internal migrants are socialised in similar conditions and embedded in similar social relations. The common conditions of socialising are the consumption milieus of moving, settling, adapting, and integrating into regional peculiarities, culture, nature, lifestyle, and social dynamics. Also, migrant groups find themselves embedded in similar social relations, as they are approached in similar ways by the region's population, social institutions, government and public offices, other social groups, and support organisations.

Based on the discussion unfolded above, the authors argue that two different paths of reasoning are available to analytically identify a collectivity: objectivist and relational. The objectivist logic calls for examination of cultural understandings of individual members and assigning them to different groups on the basis of their similarity in cultural understanding. This is about maximising homogeneity within a segment and heterogeneity between the segments. From a cultural standpoint, the analyst would explain the formation of a collectivity as the process of developing homogenous cultural understandings in relation to the product. This line of thought is somewhat paradoxical. As the collectivity definition deemphasises the role of an internal conscious apparatus in collectivity formation, the proposed thesis of increased homogeneity in understanding implies explicit interaction among the members of a group. The relational standpoint refutes the idea that homogeneity is the consequence of objective cultural judgement. It is argued that a collectivity is formed through members' intentional practices of differentiating themselves from other migrant groups. The homogeneity within the segment is accepted as the consequence of the members acting to attain maximum heterogeneity.

\section{Symbolism of lifestyles}

Holt (1997) undertook a poststructuralist study investigating consumer collectivities expressed in different lifestyles. Holt argued that lifestyles are symbolic collective constructions built via drawing meaningful boundaries between different consumption patterns. He defined consumption patterns as "regularities in consumption behaviour" (p.337). The symbolic nature of a lifestyle is reflected in its quality of being in a relational unity with another lifestyle. Holt gives the example of ascetic lifestyles that are based on denial of material comforts of life only being meaningful in opposition to lifestyles based on hedonistic consumption. Consumers are seen creating meaning of their identity by describing what they are not. In other words, they position themselves against opposing lifestyles and attribute meaning to actions performed by individuals who are supposed to represent those lifestyles. In describing such distinction creation, Holt propounds the relational logic to understanding lifestyles: they cannot be described as cultural values shared by individuals subjectively as proposed by VALS (values, attitudes, and lifestyles) approach; rather they have social origins and are based on differences observed by consumers. 
Holt identifies two important symbolic boundaries which dissect four lifestyles: the national/local boundary that structures the activities of the middle class, namely the working class and the centre/periphery boundary that organises the lifestyles of the dominant versus the dominated. Holt observes that the members of the middle class see themselves acting at a national or international scope. They aspire to such activities (e.g. international travel, and leisure activities) which would spare them from becoming "too invested in the local community" (p. 336). At the same time, the working class is bound to their locality and engage in activities (e.g. camping, hunting, and gardening) that are valued because of their difference to urban lifestyle that is considered to be "dangerous, (too) fast paced, and unfriendly" (p. 336). The important aspect of Holt's analysis is the fact that his respondents described their lifestyle by distancing themselves from an opposing lifestyle. Similarly, Holt observes the centre/periphery boundary in lifestyles dormant in central Pennsylvania. Especially, the town status lifestyle associated with the regional university's cultural, social, and economic impact is seen to dominate everyday life practices. In opposition to this lifestyle is the rural folkways lifestyle which is based on avoiding everything that can be associated with the university. The rural folkways lifestyle expresses attitudes and activities that are at the periphery of the cultural framework such as hunting, fishing, and participating at local festivities. While the town status lifestyle is based on strong affective and emotional attachment to university-associated institutions, sites, morals, and values, the rural folkways' lifestyle is built on a strong despise towards the university culture.

\section{Conceptual framework}

Based on the literature review, the expectation is that migrant clusters reference other migrant classes via direct opposition in valuing a place (Figure 1). At least, one must be able to distinguish a pair of clusters that are linked in their opposition to each other. In the case of four clusters, two pairs of clusters should be different and thus express a common lifestyle. The differences between lifestyles are accepted to be differences in their valuation of the place.

Lifestyles are the universal phenomena and traditional interpretive methods are likely to fail to identify them. A research strategy that we offer identifies lifestyles via the use of cluster analysis, planned contrasts, and relevant interpretation. The identified holistic and fragmentalist lifestyles indicate that a place is approached as the object of value creation (Vargo and Lusch, 2004). In other words, this investigation indicates that the place (e.g. Hawke's Bay region in this study) is an equivocal marketing object. In other words, it is a brand that could have different meanings and value to different customer clusters.

\section{Research methodology}

Study context

The Hawke's Bay region is situated on the east coast of the North Island of New Zealand. Its land area size is 14,200 square kilometer ${ }^{2}$ with the estimated population of 147,783 .
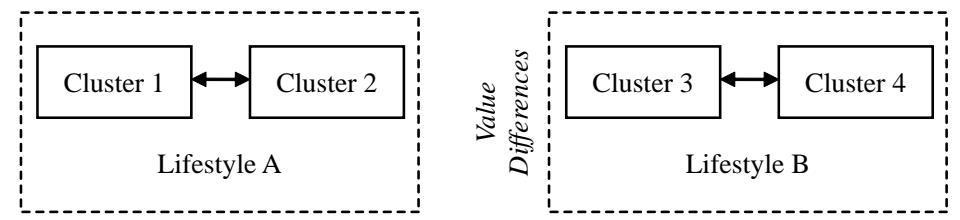

Figure 1. The formation of migrant collectivities and lifestyles 
JPMD

3,3

172
Hawke's Bay is known for its sunny climate, fabulous beaches, sheltered coastal plains, and long-established vineyards. The general perception of Hawke's Bay as to why people from other regions want to move here are the following: superior quality of lifestyle, laid-back environment, lack of the hustle and bustle of large cities, good place for bringing-up children, and the weather - mostly sunny, warm days. With the above offerings, Hawke's Bay has not only attracted visitors but also residents from other regions of New Zealand and overseas.

\section{Survey development and data collection}

A structured questionnaire focusing on the research objectives was developed for collecting data. The questionnaire was pre-tested by Hawke's Bay Incorporated and Department of Labour. A cover letter explaining the purpose of this research to the respondent was attached to the questionnaire. The postal mail method was used for sending out the questionnaire. A post-paid envelope for the respondents to send back their completed questionnaire was utilised to speed up the process. New Zealand Post provided the database of migrants who gave their household redirection contacts in Hawke's Bay since 2004. The database consists of 2,018 contacts. All the contacts on the database were used for this research. Response rate was 500 but only 381 responses were found to be usable because the discarded responses had either response error, i.e. several critical questions were not answered or sampling error, i.e. responses from people who were not migrants but had lived in Hawke's Bay all their life. Five weeks were allocated for the respondents to complete their questionnaires and return to Hawke's Bay Incorporated.

\section{Measurement and reliability}

To derive constructs that are used as clustering bases, 12 items measuring the importance of the regional features that affect migrants' decision to move to Hawke's Bay are selected. To detect underlying constructs, we undertake factor analysis, the extraction method being principal components with a varimax rotation (Table I). Three factors are identified that explain 63.64 percent of the total variance. Although this indicator is not greatly satisfactory, the importance of the analysis is that the different groups of the variables are identified. In other words, the purpose is to explore ways through which a big number of variables can be represented by a small number of underlying constructs. The variables racial integration, level of crime, unpolluted environment, and friendly people load on the first factor that is interpreted as a social environment (considering pollution being associated with overcrowding and population density). The variables lifestyle, unstressful living, climate, and naturally beautiful load on Factor 2 that is associated with the natural environment. The variables finding work, career advancement, business opportunities, and commuting times load on Factor 3 that is interpreted as the business environment (Table I).

The data adequacy for factor and cluster analysis has been tested via Kaiser-Meyer-Olkin measure of sampling adequacy. The value obtained 0.873 is satisfactory suggesting that factor analysis is useful with the data at hand. Bartlett's Test of sphericity $\left(\chi^{2}=1878.23, \mathrm{df}=66\right.$, sig. $\left.=0.000\right)$ indicated that there are significant relationships between variables and that factor analysis is appropriate in this case. Based on these results, we define three multi-item constructs - Natural Environment Importance (NEI), Social Environment Importance (SEI), and Business Environment 


\begin{tabular}{|c|c|c|c|c|}
\hline & 1 & $\begin{array}{c}\text { Components } \\
2\end{array}$ & 3 & of place \\
\hline Racial integration & 0.809 & 0.096 & 0.196 & \\
\hline Level of crime & 0.767 & 0.318 & 0.103 & \\
\hline Unpolluted environment & 0.707 & 0.438 & 0.183 & \\
\hline Friendly people & 0.575 & 0.395 & 0.192 & 173 \\
\hline Lifestyle & 0.179 & 0.812 & 0.200 & \\
\hline Unstressful living & 0.374 & 0.715 & -0.017 & \\
\hline Climate & 0.197 & 0.745 & 0.113 & \\
\hline Naturally beautiful & 0.514 & 0.591 & 0.131 & \\
\hline Finding work & -0.012 & 0.084 & 0.815 & Table I. \\
\hline Career advancement & 0.296 & -0.069 & 0.797 & Rotated component \\
\hline Business opportunities & 0.285 & 0.123 & 0.691 & matrix from factor \\
\hline Commuting times & 0.047 & 0.300 & 0.550 & analysis \\
\hline
\end{tabular}

Importance (BEI) - which are given in Appendix 1, Table AI. The acceptable values of the Coefficient alpha suggest that the scales are reliable. These constructs are then modified into standardized variables with mean 0 and a unitary standard deviation, i.e. $Z$-scores (zNEI, zSEI, and zBEI). Furthermore, we develop measures of satisfaction with the environment: Natural Environment Satisfaction (NESat), Social Environment Satisfaction (SESat), and Business Environment Satisfaction (BESat) (refer to Appendix 1, Table AI). The coefficients (Cronbach's alpha) for these constructs are reported and all of them are satisfactory.

\section{Method}

We undertake hierarchical cluster analysis to identify a possible number of natural clusters within the data set. Based on the agglomeration schedule and the dendrogram, we conclude that there are four unique groups of respondents. Selecting zNEI, zSEI, and zBEI as clustering bases, we carry out K-means cluster analysis with a pre-specified four-cluster solution.

Comparisons between clusters are undertaken through carrying out planned contrasts within the framework of generalized linear model I (analysis of variance). A set of orthogonal codes was used to derive three dummy variables. D1 expresses differences between the average means of the two pairs of contrasting clusters, i.e. "Cluster 1/Cluster 2" versus "Cluster 3/Cluster 4". D2 represents differences between Cluster 1 and Cluster 2, whereas D3 represents differences between Cluster 3 and Cluster 4 . The adequacy of orthogonal coding is assured by checking whether the vertical sums and the total of products of the codes equal to zero (Table II). In the planned contrasts tests, the dependent variables were age, income, the number of years spent in Hawke's Bay, and the number of years migrants intend to stay in Hawke's Bay.

We apply binomial logistic regression to determine particular migrant characteristics, activities, and choices that are predictive of lifestyle choices.

\section{Analysis results}

We identify four different migrant clusters (Table III). The biggest cluster in terms of size is Cluster 2 named Material Success Seekers. It comprises migrants who are in the 
JPMD

3,3

\section{4}

region to pursue business, career, and job opportunities. They deemphasise the importance of the region's natural and social resources.

The next biggest group is Cluster 1, Community/Environment Folks, who give high importance to the unique social and natural environments of the region, while paying no heed to materialistically driven motives. It is critical to note that Community/ Environment Folks' preferences are in direct opposition to those of Material Success Seekers. These two clusters in relation (or opposition) make up a common system that we choose to call the fragmentalist lifestyle because these two clusters emphasise a particular feature (fragment) of the place.

Cluster 3 makes up 27.5 percent of the sample. They approach the regional opportunities holistically and consider all three environments to be very important. For them, Hawke's Bay is a "promised land" where they can work and also enjoy the region's natural and social advantages. We name this group "All-rounders". In direct opposition to All-rounders are Apathetics (Cluster 4) who also approach the issue holistically but with a different tact. This group of migrants assume an "uninterested" status with regard to all three regional characteristics. Most probably, these migrants were forced to move to the region due to different life circumstances. The opposition between All-rounders and Apathetics is labelled as the holistic lifestyle.

The planned contrasts reveal the nature of socioeconomic polarisation between migrant collectivities (Table IV). In this context, D1 is the measure of differences between the fragmentalist lifestyle and the holistic lifestyle in the mean levels of dependent variables. D2 shows how Community/Environment Folks are different to Material Success Seekers, while D3 compares Apathetics to All-rounders.

Table II. Orthogonal codes

\section{Clusters}

D1 ( contrast $\left._{1}\right)$

D2 (contrast 1 )

D3 ( contrast $\left._{1}\right)$

Product $(\mathrm{D} 1 \times \mathrm{D} 2 \times \mathrm{D} 3)$

\section{Cluster 1}

Cluster 2

Cluster 3

Cluster 4

Total

$\begin{array}{rr}-1 & 0 \\ 1 & 1 \\ 1 & -1 \\ -1 & 0 \\ 0 & 0\end{array}$

1
0
0
-1
0

0

0

0

0

0
Table III.

Cluster centroids and sizes

\begin{tabular}{|c|c|c|c|c|c|}
\hline Clusters & zNEI & $\begin{array}{l}\text { uster centroi } \\
\text { zSEI }\end{array}$ & zBEI & Number of cases & Cluster size $(\%)$ \\
\hline $\begin{array}{l}\text { Cluster 1: community/ } \\
\text { environment folks }\end{array}$ & $\underset{(0.54944)}{+}$ & $\begin{array}{c}+ \\
(0.33957)\end{array}$ & $\begin{array}{c}- \\
(-0.72276)\end{array}$ & 112 & 29.3 \\
\hline Cluster 2: material & - & - & + & & \\
\hline success seekers & $\begin{array}{c}(-0.45229) \\
++\end{array}$ & $\begin{array}{c}(-0.51231) \\
++\end{array}$ & $\begin{array}{c}(0.31334) \\
++\end{array}$ & 122 & 32.1 \\
\hline Cluster 3: all-rounders & $\begin{array}{c}(0.65426) \\
--\end{array}$ & $\begin{array}{l}(0.89313) \\
--\end{array}$ & $\begin{array}{c}(0.98963) \\
-\end{array}$ & 105 & 27.5 \\
\hline Cluster 4: apathetics & $(-1.78700)$ & $(-1.65019)$ & $(-1.45687)$ & 42 & 11.1 \\
\hline
\end{tabular}

Notes: The signs $(-)$ or $(--)$ indicate the extent to which the centroid is less than the mean value; the signs $(+)$ or $(++)$ indicate the extent to which the centroid is greater than the mean value 


\begin{tabular}{|c|c|c|c|c|c|c|}
\hline Dependent variable & Levene's test & Contrast & $\begin{array}{l}\text { Value of } \\
\text { contrast }\end{array}$ & $\begin{array}{l}\text { Standard } \\
\text { error }\end{array}$ & $t$ & of place \\
\hline \multirow[t]{3}{*}{ Age } & Variances are equal (Levene's & D1 & 2.3298 & 2.82955 & 0.823 & \\
\hline & statistic $=1.64 ;$ sig. $=0.179)$ & D2 & 10.0749 & 1.64842 & $6.112^{* *}$ & \\
\hline & & D3 & 9.9286 & 2.29979 & $4.317^{* *}$ & \\
\hline \multirow[t]{2}{*}{ Income } & Variances are equal (Levene's & $\mathrm{D} 1$ & 6.3909 & 7.76133 & $0.823 *$ & 175 \\
\hline & statistic $=0.324 ;$ sig. $=0.808)$ & $\begin{array}{l}\text { D2 } \\
\text { D3 }\end{array}$ & $\begin{array}{l}-10.6303 \\
-22.4850\end{array}$ & $\begin{array}{l}4.45587 \\
6.35479\end{array}$ & $\begin{array}{l}-2.386^{*} \\
-3.538^{* *}\end{array}$ & \\
\hline Years living in & Variances are equal (Levene's & D1 & -0.1010 & 0.19853 & -0.509 & \\
\hline \multirow[t]{2}{*}{ Hawke’s Bay } & statistic $=0.458 ;$ sig. $=0.712)$ & D2 & 0.1504 & 0.11566 & 1.300 & \\
\hline & & D3 & 0.0549 & 0.16136 & 0.340 & \\
\hline Years to stay in & Variances are not equal (Levene's & s D1 & 0.6316 & 0.87258 & 0.724 & \\
\hline \multirow[t]{2}{*}{ Hawke’s Bay } & statistic $=16.80 ;$ Sig. $=0.000)$ & $\mathrm{D} 2$ & 1.5186 & 0.43261 & $3.510^{* *}$ & Findings from the \\
\hline & & D3 & -0.5750 & 0.75778 & & planned contrasts \\
\hline \multicolumn{6}{|c|}{ Note: Significance at: ${ }^{*} \alpha=0.05$ and ${ }^{* *} \alpha=0.01$} & \\
\hline
\end{tabular}

It is important to note that the fragmentalist lifestyle and the holistic lifestyle followers do not differ from each other in terms of age, income, the number of years lived in the region, and intended number of years to stay in the region. This is indicated by insignificant D1 coefficients for all four contrasts. Within the fragmentalist lifestyle, Community/Environment Folks are significantly older than Material Success Seekers while having less disposable income. While these groups are on a par with the number of years lived in the region, the former group intends to stay longer in the region compared to the latter one. In the holistic lifestyle, Apathetics are older than All-rounders while enjoying significantly less income levels. These groups are not different in terms of the years spent in the region and the intended number of years to stay in the future (Table V).

Logistic regression shows that the odds of qualifying as a Material Success Seeker rather than a Community/Environment Folk are 3.06 times higher for couples with children and 12.13 times higher for non-family households. Migrants working in managerial positions are 6.24 times more likely to be a Material Success Seeker rather than a community/environment folk. The same is true for professionals (8.48 times). There are no differences between these groups in terms of gender and the other family status groups and occupations. Also, the odds of being a Material Success Seeker are 4.76 times less when there is 1 unit increase in the rate of NESat (Table VI).

In the case of the holistic lifestyle clusters, the odds of being All-rounder but not Apathetic are 42 (!) times greater for migrants doing office work. No differences were discovered in terms of gender and the family status groups, occupations, and satisfaction scores except BESat. This means that the odds of being an All-rounder increase 4.86 times for each 1 unit increase in the rate of BESat.

\section{Discussion of findings}

The research findings support a theoretical expectation that consumption patterns substantially structure the interrelation of lifestyle collectivities. This structuring 
${ }_{3,3}$

Table V.

Predictors of collectivity choice

\begin{tabular}{lllllr}
\hline Predictor & Coef. & SE coef. & \multicolumn{1}{c}{$Z$} & \multicolumn{1}{c}{$p$} & Odds ratio \\
\hline Constant & 4.24739 & 1.20416 & 3.53 & 0.000 & \\
Gender & 0.0335948 & 0.335558 & 0.10 & 0.920 & 1.03 \\
Family status (single = O) & & & & & \\
1. Couple, no child(ren) & 0.359871 & 0.477829 & 0.75 & 0.451 & 1.43 \\
2. Single, child(ren) & 0.450974 & 0.776328 & 0.58 & 0.561 & 1.57 \\
3. Couple, child(ren) & 1.11869 & 0.477858 & 2.34 & 0.019 & 3.06 \\
4. Non-family household & 2.49548 & 1.28697 & 1.94 & 0.052 & 12.13 \\
Occupation (elementary occupation (e.g. cleaner, caretaker, and labourer) & $=0)$ & & \\
1. Managerial position & 1.83084 & 0.505432 & 3.62 & 0.000 & 6.24 \\
2. Professional (e.g. doctor and teacher) & 2.13770 & 0.462484 & 4.62 & 0.000 & 8.48 \\
3. Clerk (e.g. office work) & 1.17804 & 0.803301 & 1.47 & 0.143 & 3.25 \\
4. Services and sales & -0.0042257 & 0.696309 & -0.01 & 0.995 & 1.00 \\
5. Agricultural worker & 0.992599 & 0.619242 & 1.60 & 0.109 & 2.70 \\
6. Trades (e.g. construction worker) & 0.910806 & 0.622398 & 1.46 & 0.143 & 2.49 \\
NESat & -1.56573 & 0.353239 & -4.43 & 0.000 & 0.21 \\
SESat & -0.351745 & 0.326351 & -1.08 & 0.281 & 0.70 \\
BESat & 0.0944323 & 0.148204 & 0.64 & 0.524 & 1.10
\end{tabular}

Note: Material Success Seekers $=1$ versus Community/Environment Folks $=0$

\begin{tabular}{lllllr}
\hline Predictor & Coef. & SE coef. & $Z$ & $p$ & Odds ratio \\
\hline Constant & -6.87334 & 1.69717 & -4.05 & 0.000 & \\
Gender & -0.595838 & 0.674662 & -0.88 & 0.377 & 0.55 \\
Family status (single = 0) & & & & & \\
1. Couple, no child(ren) & 0.168769 & 0.812136 & 0.21 & 0.835 & 1.18 \\
2. Single, child(ren) & 2.65247 & 1.91370 & 1.39 & 0.166 & 14.19 \\
3. Couple, child(ren) & 0.363314 & 0.811737 & 0.45 & 0.654 & 1.44 \\
4. Non-family household & -0.915242 & 1.43695 & -0.64 & 0.524 & 0.40 \\
Occupation (elementary occupation (e.g. cleaner, caretaker, and labourer $=0)$ & & \\
1. Managerial position & 1.24891 & 1.00938 & 1.24 & 0.216 & 3.49 \\
2. Professional (e.g. doctor and teacher) & 0.470780 & 0.770055 & 0.61 & 0.541 & 1.60 \\
3. Clerk (e.g. office work) & 3.73555 & 1.64063 & 2.28 & 0.023 & 41.91 \\
4. Services and sales & 4.09900 & 2.96212 & 1.38 & 0.166 & 60.28 \\
5. Agricultural worker & 2.08209 & 1.44932 & 1.44 & 0.151 & 8.02 \\
6. Trades (e.g. construction worker) & 1.52761 & 1.15806 & 1.32 & 0.187 & 4.61 \\
NESat & 0.792485 & 0.524897 & 1.51 & 0.131 & 2.21 \\
SESat & 0.490405 & 0.559381 & 0.88 & 0.381 & 1.63 \\
BESat & 1.58194 & 0.488413 & 3.24 & 0.001 & 4.86
\end{tabular}

Table VI.
Predictors of collectivity choice

Note: All-rounders $=1$ versus Apathetics $=0$

happens in a way that collectivities form in closely related pairs rather than existing in themselves as autonomous groups. The analysis shows that Material Success Seekers are identified by their unique attitude of assigning different levels of importance to the regional characteristics that are in direct opposition to those of Community/Environment Folks. Material Success Seekers strongly emphasise the business environment and maintain a somewhat apathetic approach towards regional natural/social opportunities. 
They thus create their unique "me" that is differentiated from the identity of Community/ Environment Folks who strongly value the region's natural and social aspects. Consistent with Bourdieu's (1984) observation, we find that tastes for complex products are political and rooted in social processes of social distinction creation. The fact that relational commonalities are found in the existing migrant clusters lends support to the concept "habitus", because we observe a global social pattern in self-reported data retrieved from research participants' individual conscious structures. In this sense, individual consciousness can be taken as the expression of societal structures, as argued by Bourdieu. In particular, the planned contrasts and logistic regression results help us examine the contexts in which the specific material success seeking or community/ environment habita are moulded. The material success habitus is contracted in contexts where relatively younger, excessively high-income migrants with managerial or professional occupations primarily living in non-family households interact and socialise. In contrast, the community/environment habitus is bred in social contexts attributed to relatively older migrants with high- to moderate-income levels and non-managerial occupations living in family households. Another important point to note is that the community/environment habitus significantly increase the odds of feeling higher degrees of satisfaction with the regions' environmental resources. In other words, the material success habitus can be associated with growing "blind" or increasing discontent towards what is on offer in the region's natural environment. This may also indicate that Material Success Seekers are able to draw comparisons between affordable natural resources nationwide or overseas, while the reference horizon of Community/Environment Folks are dominated only by regional/local opportunities.

The collectivities, Material Success Seekers and Community/Environment Folks, in their contrast and interdependence give rise to a unique lifestyle which, we identify as the fragmentalist lifestyle. Hence, we note that a lifestyle can be interpreted as a meta-collectivity, i.e. the structure that bridges collectivities at a higher abstraction level and therefore becomes somewhat inaccessible to direct observation and consciousness. Similarly, another meta-collectivity forms in the opposition between All-rounders and Apathetics. All-rounders grant high significance to all three regional environments, while Apathetics differentiate themselves through maintaining indifference with regard to these resources in totality. The planned contrasts and logistic regression indicate that the All-rounders are younger relative to Apathetics and have considerably higher income. Migrants doing office work are more likely to be All-rounders and less likely to be an Apathetic. As per satisfaction with the regional resources, 1 unit increase with the BESat score more than quadruples the odds of becoming an All-rounder. These findings suggest that the All-rounder habitus is likely to develop among the younger cohorts of population with high-income and office-related occupations. The satisfaction with the business environment is another determinant. Apathetics are older, have less income, less likely to hold an office-related occupation, and are not satisfied with the business environment in the region.

Moreover, this analysis detects a meta-opposition between the fragmentalist lifestyle and the holistic lifestyle. The fragmentalist lifestyle signifies a tendency to emphasise a particular fragment of the place over its other fragments. The fragmentalist attitude is in contrast to the "integrative" predisposition of the holistic lifestyle. The holistic lifestyle followers do not consider the place-as-product to consist of fragments; rather they accept it in its entirety. Three theoretical perspectives underpin these findings.
Customers of place

177 
JPMD

3,3

178
From the perspective of the service-dominant logic of marketing, two different conceptual approaches in comprehending products can be distinguished. Consumers could either take a product as a collection of its physical attributes or they can think of it in terms of services that transmit holistic experience (Vargo and Lusch, 2004). The fragmentalist lifestyle is possibly the expression of the former approach where migrants tend to see the region in the light of its concrete characteristics. The holistic lifestyle followers may be apprehending the place as a service that delivers whole experience which is undividable. From the perspective of existential phenomenology, consumers may situate the region and its attributes within the figure-ground framework (Thompson et al., 1989). Within the fragmentalist lifestyle, when a migrant focuses on a particular regional characteristic (e.g. business environment), the other characteristics tend to recede into background. For Material Success Seekers, the figure is the business environment and the ground is the natural and social environments, whereas for the Community/Environment Folks, the figure is the natural/social environment and the ground is the business environment. For the holistic lifestyle, the region as a whole is taken as the figure while other comparable regions may be taken as the ground. From the value research perspective, the place-as-product can represent an object that can contain different types of value. Podolny and Hill-Popper (2004) differentiate between the hedonic and transcendent conceptions of value. They argue that the hedonic conception of value involves making judgments about art objects based on a fixed set of attributes. In his case, a complex product is reduced into a collection of characteristics and compared to other objects along these characteristics. In this research, the fragmentalist lifestyle migrants are seen making comparisons between New Zealand regions on different attributes. They tend to simplify the complexity of apprehending the place-as-product by fragmenting it into several concrete dimensions that allows them to make comparisons. The transcendent conception of value involves emotional, aesthetic attachment to a complex object. The object is not decomposed into manageable dimensions. It is taken as a whole that delivers holistic enjoyment or experience. The holistic lifestyle migrants' holistic attitude can well be the consequence of understanding the value of the place-as-product transcendentally.

Also, the planned contrasts show that even though there are differences between the identified collectivities in terms of age, income, and the number of years spent in the region, there was no evidence to suggest that lifestyles 1 and 2 are different in these terms. The insignificant coefficients on D1 suggest that Holt's (1997) contention that lifestyles are universal phenomena and that they cannot be detected via demographic profiling is supported. The results indicate that lifestyles are not readily observable via traditional methods of market segmentation because they arise as symbolic boundaries in social interaction milieus and not as fixed boundaries at the level of social class characteristics.

\section{Implications}

\section{Theoretical implications}

There are several important theoretical implications of this investigation. We note that little research is dedicated to studying internal migrants as place customers and there is no research known to the authors that investigates internal migrant segments as lifestyle-based collectivities. This investigation attempts at closing this gap. Also, we augment the theory of migrant cluster formation via our thesis that migrant clusters are collectivities in opposition and that they express specific lifestyles. In this vein, 
we offer the theory of migrant collectivity formation. According to this theory, migrants' individual thoughts are structured as habita, i.e. the mental expression of social and political structures in society. The relevant habitus leads migrants to socialise in particular environments and thus take significant others' behaviour as a point of reference. For example, migrants who differentiate themselves from Material Success Seekers form a collectivity that we call Community/Environment Folks. In the same way, All-rounders are a group of people who represent the mirror image of Apathetics. This process indicates that migrant collectivities are formed as a result of primarily distinction building.

\section{Implications for design of regional services}

The regional and city councils oversee the general design of services, facilities, public spaces, and other infrastructure that can have strong appeal in attracting skilled migrants to the region. We suggest that these decision makers should recognise the cultural dynamics of migrant collectivity formation. For example, one of the possibly advantageous strategy directions is to develop natural and environmental resources that people can enjoy (e.g. parks, access points to forests, lakes, and rivers, beaches, lookouts, tramping, and cycling routes). This would certainly appeal to Community/Environment Folks and may receive controversial resonance in other migrant clusters. The Material Success Seekers in their opposition to the former collectivity may reverse the normality and develop excessive antipathy towards the local natural resources. This may not have desired effect on All-rounders and Apathetics (the holistic lifestyle) either, because of their emphasis of totality rather than fragments. Hence, different habita developed in various social milieus moderates the satisfaction with particular regional resources.

\section{Implications for information dissemination}

Designing regional services is simply one side of the equation, whereas the other side is reaching out migrant segments via effective and relevant communication about available resources. This is the task of the settlement support agency. The knowledge of different clusters and their preferences is instrumental and essential in designing effective marketing communications about the place. The settlement support agency would increase effectiveness and appeal of communication if it approached different collectivities through variable creative messages, media combination, and success criteria rather than treating all migrants as one single mass market.

\section{References}

Anderson, E., Chakrapani, C. and Hernandez, T. (2009), "Marketing the downtown through geographically enhanced consumer segmentation", Journal of Place Management and Development, Vol. 2 No. 2, pp. 125-39.

Ashworth, G.J. and Voogd, H. (1990), Selling the City: Marketing Approaches in Public Sector Urban Planning, Belhaven, London.

Bourdieu, P. (1984), Distinction: A Social Critique of the Judgement of Taste, Routledge \& Kegan Paul, London.

DeWind, J. and Holdaway, J. (Eds) (2008), Migration and Development within and Across Borders: Research and Policy Perspectives on Internal and International Migration, International Organization for Migration, Geneva. 
JPMD

3,3

Greenwood, M.J. (1997), "Internal migration in developed countries", in Rosenberg, M.R. and Stark, O. (Eds), Handbook of Population and Family Economics, Vol. 1B, North-Holland, Amsterdam, pp. 647-720.

Holt, D.B. (1997), "Poststructuralist lifestyle analysis: conceptualizing the social patterning of consumption in postmodernity", Journal of Consumer Research, Vol. 23 No. 4, pp. 326-50.

Jiwa, S.J., Coca-Stefaniak, A., Blackwell, M. and Rahman, T. (2009), "Light night: an 'enlightening' place marketing experience", Journal of Place Management and Development, Vol. 2 No. 2 , pp. 154-66.

Kavaratzis, M. and Ashworth, G. (2008), "Place marketing: how did we get here and where are we going?", Journal of Place Management and Development, Vol. 1 No. 2, pp. 150-65.

Kotler, P. and Gertner, D. (2002), "Country as brand, product, and beyond: a place marketing and brand management perspective", Brand Management, Vol. 9 Nos 4/5, pp. 249-61.

Kotler, P., Haider, D.H. and Rein, I. (1993), Marketing Places: Attracting Investment, Industry, and Tourism to Cities, States, and Nations, The Free Press, New York, NY.

Madsen, H. (1992), "Place-marketing in Liverpool: a review", International Journal of Urban and Regional Research, Vol. 16, pp. 633-40.

Muniz, A.M. Jr and O'Guinn, T.C. (2001), "Brand community”, Journal of Consumer Research, Vol. 27 No. 4, pp. 412-33.

Podolny, J.M. and Hill-Popper, M. (2004), "Hedonic and transcendent conceptions of value", Industrial and Corporate Change, Vol. 13 No. 1, pp. 91-116.

Tajfel, H. (1981), Human Groups and Social Categories: Studies in Social Psychology, Cambridge University Press, New York, NY.

Thompson, C.J., Locander, W.B. and Pollio, H.B. (1989), "Putting consumer experience back into consumer research: the philosophy and method of existential-phenomenology", Journal of Consumer Research, Vol. 16 No. 2, pp. 133-46.

Turner, J.C. (1985), "Social categorization and the self-concept: a social cognitive theory of group behaviour", in Lawler, E.J. (Ed.), Advances in Group Processes, Vol. 2, JAI Press, Greenwich, pp. 77-122.

Turner, J.C., Hogg, M.A., Oakes, P.J., Reicher, S. and Wetherell, M.S. (1987), Rediscovering the Social Group: A Self-categorization Theory, Basil Blackwell, Oxford.

Vargo, S.L. and Lusch, R.F. (2004), "Evolving to a new dominant logic for marketing”, Journal of Marketing, Vol. 68, pp. 1-17.

\section{Corresponding author}

Djavlonbek Kadirov can be contacted at:dkadirov@eit.ac.nz

To purchase reprints of this article please e-mail: reprints@emeraldinsight.com Or visit our web site for further details: www.emeraldinsight.com/reprints 
NEI When you recall what attracted you to Hawke's Bay, how important alpha were the following factors in your decision to move to this region? $(1=$ "least important" and $4=$ "very important"

Climate

Naturally beautiful

Unstressful living

lifestyle

SEI When you recall what attracted you to Hawke's Bay, how important were the following factors in your decision to move to this region? $(1=$ "least important" and $4=$ "very important"

Friendly people

Racial Integration

Level of crime

Unpolluted environment

BEI When you recall what attracted you to Hawke's Bay, how important were the following factors in your decision to move to this region?

$(1=$ "least important" and $4=$ "very important"

Business opportunities

Career advancement

Finding work

Commuting times

NESat How would you rate the following factors about Hawke's Bay now that you have lived here since your arrival? $(1=$ "unsatisfactory" and $4=$ "very satisfactory"

Climate

Naturally beautiful

Unstressful living

Lifestyle

When you recall what attracted you to Hawke's Bay, how important were the following factors in your decision to move to this region?

$(1=$ "least important" and $4=$ "very important"

Friendly people

Racial integration

Level of crime

SESat Unpolluted environment

BESat When you recall what attracted you to Hawke's Bay, how important were the following factors in your decision to move to this region? $(1=$ "least important" and $4=$ "very important"

Business opportunities

Career advancement

Finding work

Commuting times 